\title{
Gynecologic oncologists' attitudes and practices relating to integrative medicine: results of a nationwide AGO survey
}

\author{
Evelyn Klein ${ }^{1}$ Matthias W. Beckmann ${ }^{2} \cdot$ Werner Bader $^{3} \cdot$ Cosima Brucker $^{4}$. \\ Gustav Dobos $^{5}$ - Dorothea Fischer ${ }^{6}$ - Volker Hanf ${ }^{7} \cdot$ Annette Hasenburg $^{8}$. \\ Sebastian M. Jud ${ }^{2} \cdot$ Matthias Kalder $^{9} \cdot$ Marion Kiechle $^{1} \cdot$ Sherko Kümmel $^{10}$ \\ Andreas Müller ${ }^{11} \cdot$ Myrjam-Alice T. Müller ${ }^{12} \cdot$ Daniela Paepke $^{1}$. \\ Andre-Robert Rotmann ${ }^{13}$ - Florian Schütz ${ }^{14}$ - Anton Scharl ${ }^{15}$. \\ Petra Voiss ${ }^{5,10}$ - Markus Wallwiener ${ }^{14}$. Claudia Witt ${ }^{16}$ - Carolin C. Hack $^{2,17}$
}

Received: 2 April 2017/ Accepted: 1 June 2017/Published online: 8 June 2017

(c) The Author(s) 2017. This article is an open access publication

\begin{abstract}
Purpose The growing popularity and acceptance of integrative medicine is evident both among patients and among the oncologists treating them. As little data are available regarding health-care professionals' knowledge, attitudes, and practices relating to the topic, a nationwide online survey was designed.

Methods Over a period of 11 weeks (from July 15 to September 30, 2014) a self-administered, 17-item online survey was sent to all 676 members of the Research Group on Gynecological Oncology (Arbeitsgemeinschaft
\end{abstract}

Gynäkologische Onkologie) in the German Cancer Society. The questionnaire items addressed the use of integrative therapy methods, fields of indications for them, advice services provided, level of specific qualifications, and other topics.

Results Of the 104 respondents (15.4\%) using integrative medicine, $93 \%$ reported that integrative therapy was offered to breast cancer patients. The second most frequent type of tumor in connection with which integrative therapy methods were recommended was ovarian cancer, at $80 \%$ of the participants using integrative medicine. Exercise,
Carolin C. Hack

carolin.hack@uk-erlangen.de

1 Klinik und Poliklinik für Frauenheilkunde, Technische Universität München, Munich, Germany

2 Frauenklinik des Universitätsklinikums Erlangen, FriedrichAlexander-Universität Erlangen-Nürnberg, Comprehensive Cancer Center Erlangen-Europäische Metropolregion Nürnberg (CCC ER-EMN), Erlangen, Germany

3 Zentrum für Frauenheilkunde, Klinikum Bielefeld Mitte, Bielefeld, Germany

4 Universitätsklinik für Frauenheilkunde und Geburtshilfe, Paracelsus Medizinische Privatuniversität, Nuremberg, Germany

5 Klinik für Naturheilkunde und Integrative Medizin der Kliniken Essen-Mitte, Essen, Germany

6 Klinik für Gynäkologie und Geburtshilfe, Klinikum Ernst von Bergmann, Potsdam, Germany

7 Frauenklinik und Brustzentrum Nathanstift, Klinikum Fürth, Fürth, Germany

8 Klinik und Poliklinik für Geburtshilfe und Frauengesundheit, Universitätsmedizin Mainz, Mainz, Germany
9 Klinik für Frauenheilkunde und Geburtshilfe, PhilippsUniversität Marburg, Marburg, Germany

10 Interdisziplinäres Brustkrebszentrum der Kliniken EssenMitte, Essen, Germany

11 Frauenklinik, Städtisches Klinikum Karlsruhe gGmbH, Karlsruhe, Germany

12 Frauenarztpraxis am Hochdahler Markt, Erkrath, Germany

13 Praxis für Frauenheilkunde, Geburtshilfe und Naturheilkunde, Rodgau, Germany

14 Universitätsfrauenklinik, Universitätsklinikum Heidelberg, Heidelberg, Germany

15 Brustzentrum Klinikum St. Marien Amberg, Amberg, Germany

16 Institut für komplementäre und integrative Medizin, UniversitätSpital Zürich und Universität Zürich, Zurich, Switzerland

17 Department of Gynecology and Obstetrics, University Hospital Erlangen, Friedrich-Alexander University ErlangenNuremberg, Comprehensive Cancer Center ErlangenEuropean Metropolitan Area Nuremberg (CCC ER-EMN), Universitätsstrasse 21-23, 91054 Erlangen, Germany 
nutritional therapy, dietary supplements, herbal medicines, and acupuncture were the methods the patients were most commonly advised to use.

Conclusion There is considerable interest in integrative medicine among gynecological oncologists, but integrative therapy approaches are at present poorly implemented in routine clinical work. Furthermore there is a lack of specific training. Whether future efforts should focus on extending counseling services on integrative medicine approaches in gynecologic oncology or not, have to be discussed. Evidence-based training on integrative medicine should be implemented in order to safely guide patients in their wish to do something by themselves.

Keywords Integrative medicine - Complementary medicine - Gynecologic oncology · Breast cancer . Oncologists' attitudes · Survey

\section{Introduction}

Complementary and integrative medicine is becoming increasingly popular with gynecological patients. At present, 38-60\% of all cancer patients in Western industrialized countries take advantage of complementary and alternative medicine (CAM) during the course of their disease and to support their treatment [1]. In the case of breast cancer, the figure is even as high as $90 \%[2,3]$. Breast cancer patients and gynecological cancer patients in particular, are the group with the highest percentage usage of integrative methods $[1,4,5]$. Women's willingness to take the initiative in relation to these treatments is generally greater than men's, and women are highly motivated in relation to their disease, with good compliance and considerable perseverance.

The Academic Consortium for Integrative Medicine and Health in the USA has described integrative medicine as follows: "Integrative medicine and health reaffirms the importance of the relationship between practitioner and patient, focuses on the whole person, is informed by evidence, and makes use of all appropriate therapeutic and lifestyle approaches, healthcare professionals and disciplines to achieve optimal health and healing" [6]. In this approach, complementary methods that aim to contribute to holistic care are integrated into present-day medical practices. The complementary procedures-for the most part based on experience-are to be regarded as a supplement to the current scientific, evidence-based medical system, not as a substitute for it. We classify the integrative medicine into five sub-groups: whole medical systems (e.g., homeopathy, naturopathic treatments, Ayurveda), mind/body-based interventions (e.g., meditation, chi gong, yoga), body-based therapies (e.g., massages, sports, chiropractic), biological-based therapies (e.g., phytotherapy, vitamins, enzymes) and energy-based methods (e.g., electrotherapy, hyperthermia, ultrasound therapy). Common methods in integrative medicine include homeopathy, anthroposophic medicine, in particular mistletoe therapy, classic naturopathic treatment, phytotherapy, traditional Chinese medicine (TCM) including acupuncture, sports, nutritional approaches, vitamin products, mineral nutrients, dietary supplements and relaxation therapies [7].

Previous studies on CAM have mainly addressed the frequency and methods involved in the complementary therapies used, as well as the patients' motivation, objectives, information sources, and characteristics [8-12]. Most of the breast cancer patients show high interest in CAM $[13,14]$. However, little is known about the acceptance and use of integrative medicine by gynecological oncologists in Germany. At the moment the overall qualified access to counseling on integrative medicine is not available. There is a lack of data with regard to the provision of information, competences, qualifications, and structures. Little is also known about the concrete ways in which integrative medical therapies are implemented and used in the field of gynecology.

The present study was therefore carried out to evaluate and examine the degree of acceptance, usage, and implementation of integrative medicine among gynecological oncologists in Germany.

\section{Materials and methods}

A self-administered 17-item online survey was sent between July 15, 2014 and September 30, 2014 to all 676 members of the Research Group on Gynecological Oncology of the German Cancer Society (Arbeitsgemeinschaft Gynäkologische Onkologie, AGO).

The survey was developed and distributed by the Research Group on Integrative Medicine (AG IMed), which was founded on June 28, 2013. This group of gynecological oncologists focuses on the clinical, scientific, and organizational aspects of integrative medicine in oncology. It supports scientific research and cooperation in the field of integrative medicine and also encourages the implementation of approved integrative therapy approaches and regular consultation hours for the purpose, in order to integrate these into standard oncologic care.

For the validation, the questionnaire of the survey was tested in the AG IMed Research Group on Integrative Medicine, consisting of 20 members, and evaluated using a specially developed assessment sheet. After the validation, the questionnaire was modified with a view to improving comprehension, functionality and expenditure of time. 
The online survey was sent to all 676 members of the AGO via e-mail. Participation was voluntary and anonymous. The first e-mail and call for participation was launched in July 2014, and a reminder e-mail was sent in September to members who had not yet responded, until the original deadline had passed.

The survey contained 17 questions including demographic data and items on the use of integrative therapy methods, fields of indications, consulting services, level of specific qualifications, and other topics. There are no standardized questionnaires for professionals on this topic. So we had to develop our own questionnaire for this survey. The time required to respond to it was approximately $10 \mathrm{~min}$.

Data were analyzed using IBM SPSS Statistics, version 24 (IBM Corp., Armonk, New York, USA). Statistical evaluation consisted of descriptive analysis. Total amounts and percentages were calculated.

\section{Results}

In all, 104 of the 676 AGO members participated in the survey $(32.7 \%$ women, $67.3 \%$ men). This represents a response rate of $15.4 \%$. The respondents' median age was 47 years (range 30-71 years). The majority $(56.7 \%)$ had medical degrees (M.D./Dr. med.), and $35.6 \%$ of the responding physicians also had higher qualifications, such as associate professor or professor. Seventy-six percent of the participating members were working at certified breast cancer centers and $56.7 \%$ of them at certified gynecological oncology centers. This is consistent with the demographic structure of the AGO. The percentage of men with $66 \%$ is almost twice as high as that of women's with $34 \%$. $54.1 \%$ of the AGO members bear the title M.D., $29.3 \%$ professor and $9.2 \%$ associate professor. There are $77.4 \%$ full members and $19 \%$ associated members. The age ranges from 26 to 86 years with a mean age of 51 years.

The form of integrative therapy method most commonly recommended amongst the participants was regular physical exercise, followed by nutritional counseling and advice on dietary supplements (Fig. 1). The main indications were fatigue, nausea, depression, menopausal symptoms, and sleeping disorders (Table 1). When they were asked at which point of time they provided advice about integrative therapy, most of the oncologists indicated that it was during follow-up care for their patients. With regard to the treatment phase, counseling on integrative medicine was most frequently provided during chemotherapy (Fig. 2). Most of the physicians surveyed and using integrative medicine $(93 \%)$ reported that they used integrative therapy methods with breast cancer patients. The second largest patient group to whom integrative therapies were suggested consisted of ovarian cancer patients, at $80 \%$ of the participants using integrative medicine (Fig. 3). This is not in contrast to their statement that two-thirds stated that integrative medicine is not routinely implemented in the therapy concept, because implementation in the routine is still more than a recommendation from time to time, for example consultations of integrative medicine or professional counseling on CAM.

Counseling on applicable integrative therapies is mainly provided by the physicians themselves (93\%), and secondly by dietitians, collaborating partners (e.g., specialized centers, nonmedical practitioners, etc.), and breast care nurses (Table 2). The counseling was performed according to the differences in the professional qualification. The additional qualifications most often held by those providing advice were in naturopathy $(48.6 \%)$, followed by nutritional medicine $(30.5 \%)$ and acupuncture $(29.2 \%)$. All of these are qualifications that are officially recognized by the relevant regional medical councils. Other areas in which qualifications were held were homeopathy, traditional Chinese medicine (TCM), phytotherapy, etc. Table 3 lists the proportions of advisers holding the different types of qualifications.

Two-thirds of the gynecologic oncologists surveyed stated that integrative therapy concepts were not implemented in routine clinical work, but $64.7 \%$ of them indicated that they were planning to do so. The main reasons given in the further comments section for not implementing integrative medicine in their hospitals were staff shortages, a lack of specific knowledge and qualifications, as well as a lack of scientific evidence on the efficacy of the therapies concerned. Around half of the physicians (55.5\%) stated that integrative therapy methods are not reimbursed and are therefore not profitable for the hospitals.

\section{Discussion}

Patients with breast cancer and gynecological cancer are known to be one of the patient groups who make use of integrative medicine most often [15]. These patients wish to receive advice from their oncologists not only about conventional medicine, but also about complementary therapy methods during and after the disease [13, 16]. More and more oncologists in Germany are beginning to appreciate this need and the importance of offering professional advice regarding integrative medicine.

As the survey shows, however, there is still a lack of widespread implementation of integrative therapy approaches in routine clinical work. Only one-third of the oncologists who responded had routinely offered complementary counseling to their patients. The main reasons for this are a lack of knowledge and professional training. This 


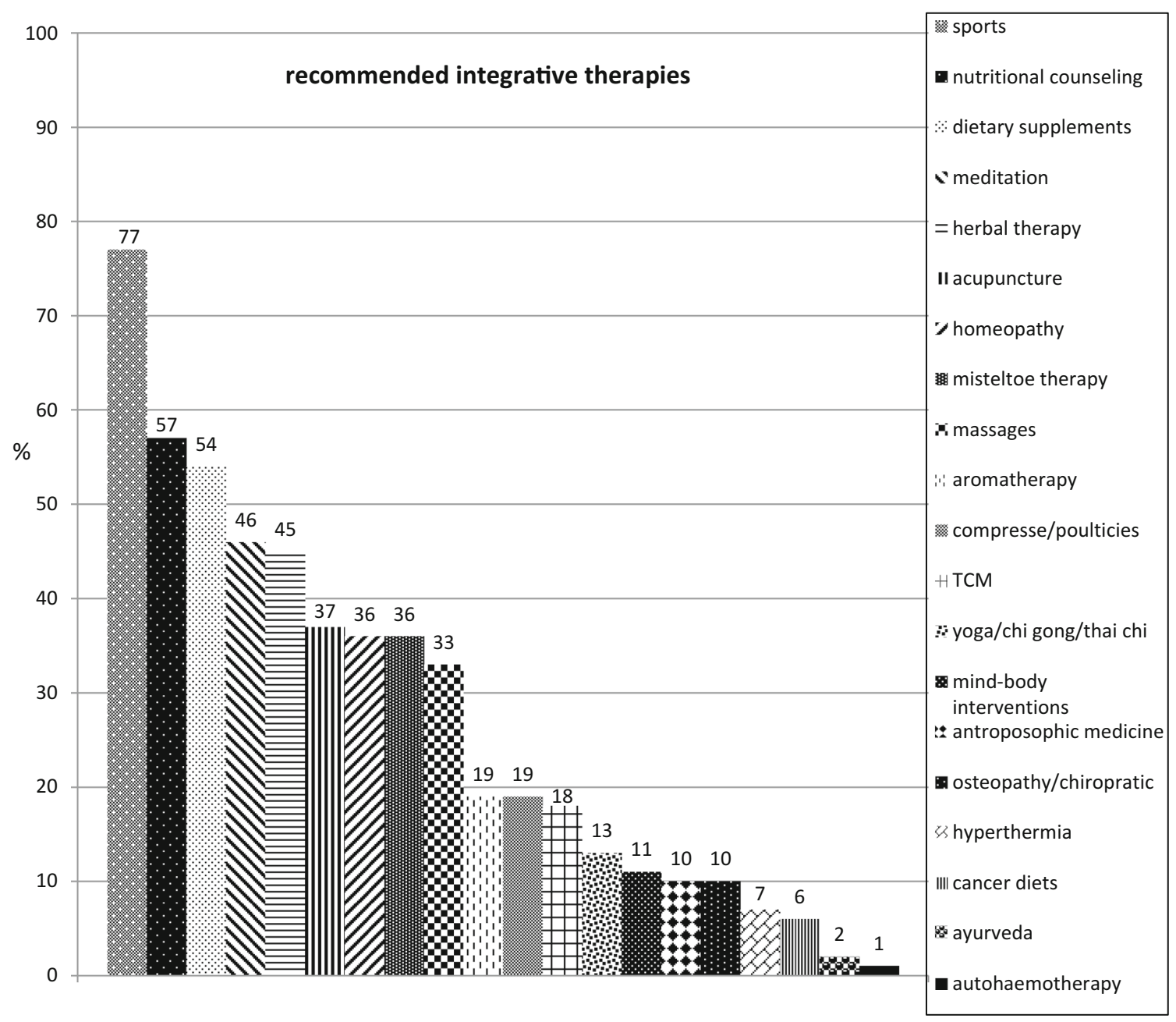

Fig. 1 Frequencies of recommended integrative therapy methods. TCM traditional Chinese medicine; $n=83$ ( $n=21$ not applicable); multiple responses were allowed

finding is consistent with the report by Muecke et al., who showed that education and training are the most essential requirements for physicians to enable them to implement CAM methods [17]. Other national and international studies have also confirmed the finding that there is generally a high level of interest in integrative therapy approaches amongst physicians, but that specific training in CAM methods is lacking [17-22]. Comparison with existing data is difficult, as the studies are not mainly aimed at oncologists, but rather at physicians in general, so that the groups of patients involved differ. Conrad et al. conducted a large survey on professionals in palliative care regarding attitudes toward CAM. Acceptance of CAM was high (92\% for complementary medicine). Only $21 \%$ think themselves adequately informed [23]. Another study evaluated the attitude of employees of a university clinic to complementary and alternative medicine in oncology is also in line with our results. Most participants were interested in complementary medicine and a substantial part would use CAM. But they were not trained on this topic [24]. In addition, most published data on complementary therapy methods have concentrated on the patient's point of view, mainly examining their acceptance and use of integrative medicine.

With regard to the patient groups identified in the present survey, the largest group to whom the oncologists recommended complementary therapies was breast cancer patients - a finding that is consistent with earlier studies [5, 25-27]. This again underlines the importance and need for gynecologic oncologists to acquire knowledge about verified integrative therapy approaches in order to offer counseling in this field.

The findings should be evaluated in light of the limitations of the study. The national survey was only addressed to AGO members and not to other hospitals or oncologists who also counsel breast cancer and gynecological cancer patients in Germany. In addition, there might have been some overlap among the responses if several AGO 
Table 1 The main indications for using integrative therapies; $n=82$ ( $n=22$ not applicable); multiple responses were allowed

\begin{tabular}{lll}
\hline Indication & $n$ & $\%$ \\
\hline Fatigue & 65 & 79.3 \\
Nausea and vomiting & 61 & 74.4 \\
Depression & 59 & 72.0 \\
Menopausal symptoms & 59 & 72.0 \\
Sleeping disorders & 59 & 72.0 \\
Loss of appetite & 58 & 70.7 \\
Joint pain & 44 & 53.7 \\
Polyneuropathy & 43 & 52.4 \\
Abdominal discomfort & 42 & 51.2 \\
Cognitive impairments & 39 & 47.6 \\
Mucositis & 35 & 42.7 \\
Hand-foot syndrome & 34 & 41.5 \\
Pain & 34 & 41.5 \\
Radiation-induced dermatitis & 30 & 36.6 \\
\hline
\end{tabular}

members from a single hospital were responding. Finally, the response rate and thus the final number of participants $(n=104)$ were quite low.

In view of the results of this survey and the existing data, future efforts should focus firstly on improving acceptance, and secondly on extending counseling services for integrative medicine approaches in gynecologic oncology. To ensure this, the existing additional training courses organized by the various regional medical councils

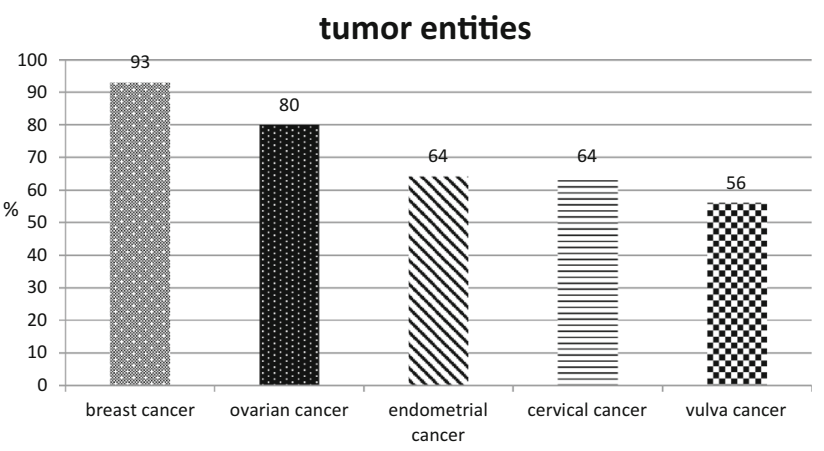

Fig. 3 Tumor entities in connection with which integrative therapies were suggested. The most common gynecological carcinomas are represented; $n=87$ ( $n=17$ not applicable); multiple responses were allowed

and specialized research groups should be taken advantage of more frequently. The aim should be to provide more gynecologic oncologists in hospitals and oncologists' offices with sound expertise, to enable them to provide guidance for patients. Particularly during the last few years, there has been increasing research and there is consequently growing evidence for integrative medicine in oncology. Although further research is still needed, oncologists can provide their patients with evidence-based treatment approaches and recommendations.

Evidence-based training on integrative medicine should be implemented in order to safely guide patients in their wish to do something by themselves. The educated

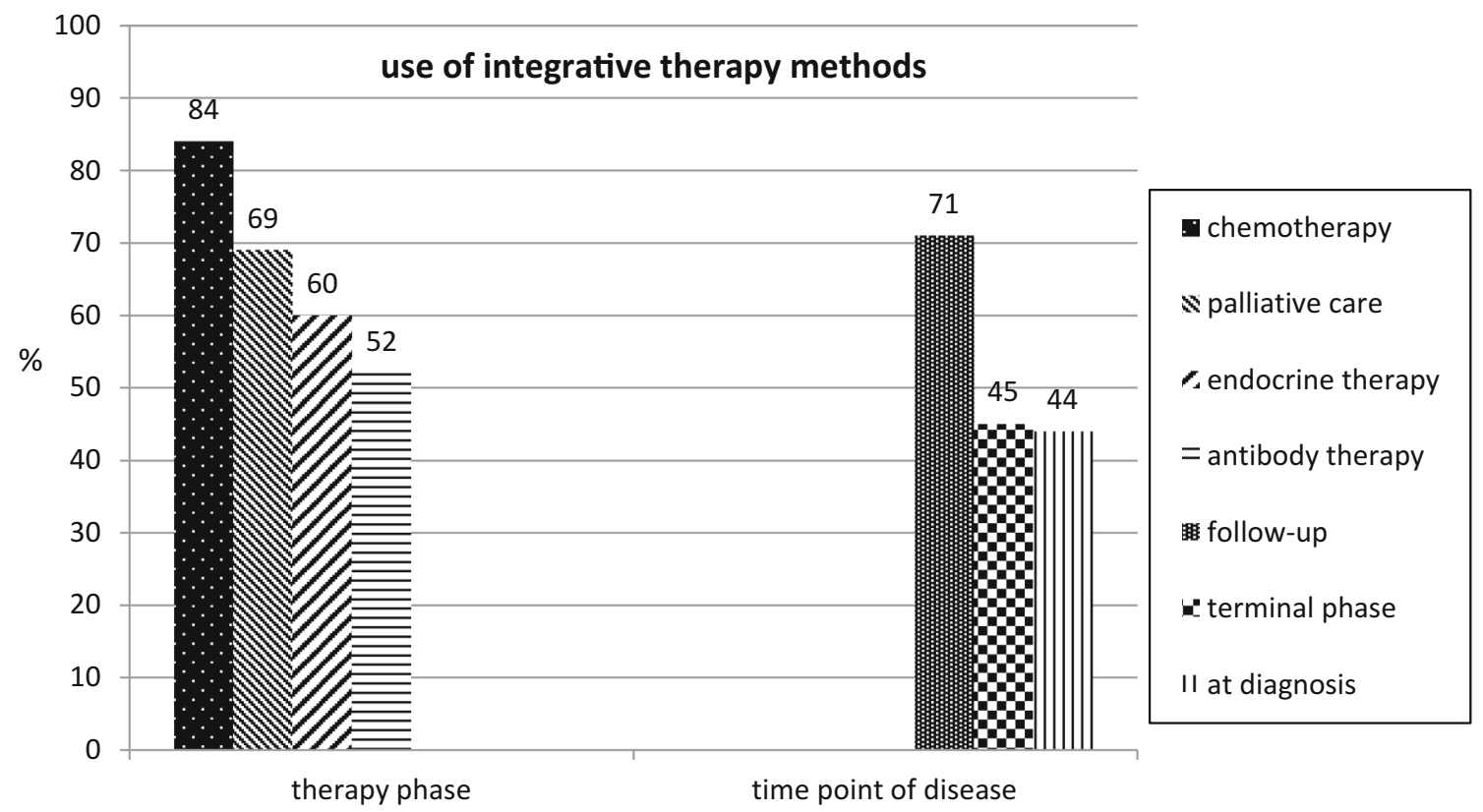

Fig. 2 Frequency with which advice about integrative therapy methods is given during specific phases of treatment and at different time points in the disease; there are no differences in the kind of methods at the different phases and time points of use; $n=86$ ( $n=18$ not applicable); multiple responses were allowed 
Table 2 Professions frequently providing counseling about relevant integrative therapies

\begin{tabular}{lcc}
\hline Profession & $n$ & $\%$ \\
\hline Physician & 80 & 92.0 \\
Nutritionist & 39 & 44.8 \\
Collaborating partners & 39 & 44.8 \\
Breast care nurse & 36 & 41.4 \\
Sports researcher & 17 & 19.5 \\
Study nurse & 10 & 11.5 \\
Mind-body therapist & 5 & 5.7 \\
\hline
\end{tabular}

Collaborating partners were, for example, clinical centers offering integrative medicine, professionals for CAM; $n=87$ ( $n=17$ not applicable); multiple responses were allowed

Table 3 Additional qualifications for therapy (registered with regional medical councils) of individuals providing advice about integrative medicine

\begin{tabular}{lcr}
\hline & $n$ & $\%$ \\
\hline Naturopathy & 35 & 48.6 \\
Acupuncture & 21 & 29.2 \\
Nutritional counseling & 21 & 29.2 \\
Homeopathy & 17 & 23.6 \\
Manual therapy/chiropractic & 6 & 8.3 \\
Further additional qualifications & & \\
Traditional Chinese medicine & 16 & 22.2 \\
Herbal therapy & 11 & 15.3 \\
Anthroposophic medicine & 10 & 13.9 \\
Neural therapy & 7 & 9.7 \\
\hline
\end{tabular}

Naturopathy, acupuncture, nutritional counseling, homeopathy and manual therapy/chiropractic are recognized qualifications for physicians in Germany; $n=72$ ( $n=32$ not applicable); multiple responses were allowed

attending physicians could better raise the topic of integrative medicine and encourage evidence-based complementary treatments for ensuring individualized, holistic, and patient-centered care.

Acknowledgements The Research Group on Integrative Medicine (AG IMed) would like to thank all of the members of the Research Group on Gynecological Oncology in the German Cancer Society (Arbeitsgemeinschaft Gynäkologische Onkologie, AGO) who took part in the survey.

Author contributions EK, $\mathrm{CCH}, \mathrm{VH}$ and SK designed the project. EK and $\mathrm{CCH}$ wrote the manuscript. MWB contributed to concept, drafting, analysis and interpretation of data. All authors collected data. $\mathrm{CCH}$ conducted data and statistical analysis. All authors read and approved the final version.

\section{Compliance with ethical standards}

Conflict of interest None of the authors reported any conflicts of interest.
Ethical approval All procedures performed in the survey involving human participants were in accordance with the ethical standards of institutional and national research committee. This article does not contain any studies with animals performed by any of the authors.

Informed consent Informed consent was obtained from all individual participants included in the survey.

Open Access This article is distributed under the terms of the Creative Commons Attribution 4.0 International License (http://crea tivecommons.org/licenses/by/4.0/), which permits unrestricted use, distribution, and reproduction in any medium, provided you give appropriate credit to the original author(s) and the source, provide a link to the Creative Commons license, and indicate if changes were made.

\section{References}

1. Horneber M, Bueschel G, Dennert G et al (2012) How many cancer patients use complementary and alternative medicine: a systematic review and metaanalysis. Integr Cancer Ther 11(3):187-203. doi:10.1177/1534735411423920

2. Münstedt K, Kirsch K, Milch W et al (1996) Unconventional cancer therapy-survey of patients with gynaecological malignancy. Arch Gynecol Obstet 258(2):81-88

3. Kreienberg R, Office des Leitlinienprogramms Onkologie (2012) Interdisziplinäre S3-Leitlinie für die Diagnostik, Therapie und Nachsorge des Mammakarzinoms: Langversion 3.0, Aktualisierung 2012, AWMF-Register-Nummer: 032-045OL. Zuckschwerdt, Germering/Munich

4. Schönekaes K, Micke O, Mücke R et al (2003) Use of complementary/alternative therapy methods by patients with breast cancer. Forsch Komplementarmed Klass Naturheilkd Res Complement Nat Class Med 10(6):304-308 (doi:75883)

5. Molassiotis A, Fernadez-Ortega P, Pud D et al (2005) Use of complementary and alternative medicine in cancer patients: a European survey. Ann Oncol 16(4):655-663. doi:10.1093/ annonc/mdi110

6. Academic Consortium for Integrative Medicine \& Health Introduction. Academic Consortium for Integrative Medicine \& Health, Mclean. https://www.imconsortium.org/about/about-us. cfm. Accessed 8 March 2017

7. Hack C, Hüttner N, Paepke D et al (2013) Integrative Medizin in der Gynäkologischen Onkologie-Möglichkeiten und Grenzen Teil 1. Geburtshilfe Frauenheilkd 73(10):R63-R80. doi:10.1055/ s-0033-1350906

8. Paul M, Davey B, Senf B et al (2013) Patients with advanced cancer and their usage of complementary and alternative medicine. J Cancer Res Clin Oncol 139(9):1515-1522. doi:10.1007/ s00432-013-1460-y

9. Tautz E, Momm F, Hasenburg A, Guethlin C (2012) Use of complementary and alternative medicine in breast cancer patients and their experiences: a cross-sectional study. Eur J Cancer 48(17):3133-3139. doi:10.1016/j.ejca.2012.04.021

10. Fasching PA, Thiel F, Nicolaisen-Murmann K et al (2007) Association of complementary methods with quality of life and life satisfaction in patients with gynecologic and breast malignancies. Support Care Cancer 15(11):1277-1284. doi:10.1007/ s00520-007-0231-1

11. Vapiwala N, Mick R, Hampshire MK et al (2006) Patient initiation of complementary and alternative medical therapies (CAM) following cancer diagnosis. Cancer J 12(6):467-474

12. Burstein HJ, Gelber S, Guadagnoli E, Weeks JC (1999) Use of alternative medicine by women with early-stage breast cancer. 
N Engl J Med 340(22):1733-1739. doi:10.1056/ NEJM199906033402206

13. Hack CC, Fasching PA, Fehm $T$ et al (2016) Interest in integrative medicine among postmenopausal hormone receptor-positive breast cancer patients in the EvAluate-TM Study. Integr Cancer Ther. doi:10.1177/1534735416668575 (Epub ahead of print)

14. Fremd C, Hack CC, Schneeweiss A et al (2017) Use of complementary and integrative medicine among German breast cancer patients: predictors and implications for patient care within the PRAEGNANT study network. Arch Gynecol Obstet. 95(5):1239-1245. doi:10.1007/s00404-017-4348-2 (Epub 2017 Mar 22)

15. Abdallah R, Xiong Y, Lancaster JM, Judson PL (2015) Complementary and alternative medicine use in women with gynecologic malignancy presenting for care at a comprehensive cancer center. Int J Gynecol Cancer 25(9):1724-1730. doi:10. 1097/IGC.0000000000000549

16. Münstedt K, Vogt T, Rabanus M-E, Hübner J (2014) Wishes and beliefs of cancer patients regarding counseling on integrative medicine. Breast Care 9(6):416-420. doi:10.1159/000368428

17. Muecke R, Paul M, Conrad C et al (2016) Complementary and alternative medicine in palliative care: a comparison of data from surveys among patients and professionals. Integr Cancer Ther 15(1):10-16. doi:10.1177/1534735415596423

18. Dahlhaus A, Siebenhofer A, Guethlin C (2015) Complementary medicine for cancer patients in general practice: qualitative interviews with german general practitioners. Forsch Komplementarmed 22(1):36-41. doi:10.1159/000375182

19. Risberg T, Kolstad A, Bremnes Y et al (2004) Knowledge of and attitudes toward complementary and alternative therapies; a national multicentre study of oncology professionals in Norway. Eur J Cancer 40(4):529-535. doi:10.1016/j.ejca.2003.11.011
20. Chang KH, Brodie R, Choong MA et al (2011) Complementary and alternative medicine use in oncology: a questionnaire survey of patients and health care professionals. BMC Cancer 11:196. doi:10.1186/1471-2407-11-196

21. Jong MC, van Vliet M, Huttenhuis S et al (2012) Attitudes toward integrative paediatrics: a national survey among youth health are physicians in The Netherlands. BMC Complement Altern Med 12:4. doi:10.1186/1472-6882-12-4

22. Blödt S, Mittring N, Schützler L et al (2016) A consultation training program for physicians for communication about complementary medicine with breast cancer patients: a prospective, multi-center, cluster-randomized, mixed-method pilot study. BMC Cancer 16(1):843. doi:10.1186/s12885-016-2884-y

23. Conrad AC, Muenstedt K, Micke O et al (2014) Attitudes of members of the German Society for Palliative Medicine toward complementary and alternative medicine for cancer patients. J Cancer Res Clin Oncol. 140(7):1229-1237. doi:10.1007/ s00432-014-1656-9 (Epub 2014 Apr 6)

24. Trimborn A, Senf B, Muenstedt K et al (2013) Attitude of employees of a university clinic to complementary and alternative medicine in oncology. Ann Oncol. 24(10):2641-2645. doi:10.1093/annonc/mdt299 (Epub 2013 Aug 13)

25. Eschiti VS (2007) Lesson from comparison of CAM use by women with female-specific cancers to others: it's time to focus on interaction risks with CAM therapies. Integr Cancer Ther 6(4):313-344. doi:10.1177/1534735407309257

26. Kalder M, Müller T, Fischer D et al (2016) A review of integrative medicine in gynaecological oncology. Geburtshilfe Frauenheilkd 76(2):150-155. doi:10.1055/s-0042-100208

27. Hack CC, Voiss P, Lange S et al (2015) Local and systemic therapies for breast cancer patients: reducing short-term symptoms with the methods of integrative medicine. Geburtshilfe Frauenheilkd 75(7):675-682. doi:10.1055/s-0035-1557748 